\title{
Baroreflex Impairment Precedes Hypertension During Chronic Cerebroventricular Infusion of Hypertonic Sodium Chloride in Rats
}

Ruben D. Buñag and Eiji Miyajima

Department of Pharmacology, College of Health Sciences and Hospital, University of Kansas Medical Center, Kansas City, Kansas 66103

bstract. Osmotic minipumps were implanted chronically for continuous $11-\mathrm{d}$ infusion of hypertonic sodium chloride $(\mathrm{NaCl})$ into the third cerebral ventricle (ICV) of awake rats to determine whether baroreflex sensitivity would be altered. Systolic and mean pressures, recorded from aortic catheters on day 11 while the rats were anesthetized with $\alpha$-chloralose, were significantly higher in rats infused with artificial cerebrospinal fluid (CSF) containing hypertonic $\mathrm{NaCl}$ than in controls similarly infused with artificial CSF alone. Reflex changes in heart rate produced by subsequent intravenous infusions of either phenylephrine or sodium nitroprusside were inhibited, but reflex changes in renal nerve activity were unaltered. Magnitude of reflex bradycardia during pressor responses to phenylephrine, as well as of reflex tachycardia during depressor responses to sodium nitroprusside, was consistently smaller in $\mathrm{NaCl}$-infused than in control rats. By contrast, group differences in attendant renal nerve firing were not significant. After sinoaortic denervation, drug-induced blood pressure effects persisted, but reflex responses in heart rate and renal nerve firing were abolished or markedly diminished. Peripheral effects produced by hypertonic $\mathrm{NaCl}$ leakage from the infusion site were considered unlikely because after 11 $\mathrm{d}$ of ICV infusion, sodium concentration, though appreciably elevated in CSF samples collected from the cisterna

Dr. Miyajima is a postdoctoral research fellow from the Second Department of Internal Medicine, Yokohama City University Medical School, Yokohama, Japan. Address correspondence and reprint requests to Dr. Buñag, University of Kansas Medical Center, Kansas City, KN 66103.

Received for publication 14 November 1983 and in revised form 10 July 1984.

J. Clin. Invest.

(c) The American Society for Clinical Investigation, Inc. $0021-9738 / 84 / 12 / 2065 / 09 \quad \$ 1.00$

Volume 74, December 1984, 2065-2073 magna, was unaffected in corresponding serum samples. When cardiovascular responses to phenylephrine were recorded while chronic ICV infusions were in progress, awake rats receiving hypertonic $\mathrm{NaCl}$ were still normotensive on day 2 yet reflex bradycardia was already attenuated. In showing that baroreflex impairment preceded the development of hypertension, our results suggest that by depressing the anterior hypothalamus, chronic ICV infusion of hypertonic $\mathrm{NaCl}$ reduces sympatho-inhibition, and the ensuing baroreflex impairment then elevates blood pressure. However, other mechanisms could also be involved.

\section{Introduction}

Ever since McCubbin et al. (1) first showed that carotid sinus baroreceptor sensitivity is reduced in renal hypertensive dogs, impaired baroreflex buffering has often been implicated as a permissive mechanism that allows blood pressure to remain elevated not only in experimental (2-4) but also in clinical (5-7) hypertension. Baroreflex dysfunction has usually been attributed to either receptor degeneration or decreased arterial wall compliance, which presumably 'reset' the baroreceptors to operate at higher pressures. Recent evidence suggests, however, that the site of dysfunction may be central rather than peripheral. Thus, clonidine, an antihypertensive drug that lowers blood pressure by reducing sympathetic vasomotor tone through stimulation of medullary $\alpha_{2}$-adrenergic receptors, has been shown to increase baroreflex sensitivity in renal hypertensive rabbits (8). Conversely, depressor and sympatho-inhibitory responses produced by activating baroreceptor afferents (i.e., through electrical stimulation of the aortic depressor nerves) are smaller in spontaneously hypertensive than in KyotoWistar normotensive rats (9).

Central mechanisms that could elevate blood pressure by increasing sympathetic vasomotor tone can likewise be stimulated by increased dietary salt intake. Excessive salt ingestion increases blood pressure and sympathetic nerve activity in Sprague-Dawley rats, and both effects can be prevented by 
destroying the ventromedial hypothalamus (10). And when hypertension is induced by DOCA-salt pretreatment, norepinephrine turnover decreases in the hypothalamus and brain stem $(11,12)$. Furthermore, in Dahl salt-sensitive rats, increased dietary salt intake enhances pressor responses to hypothalamic stimulation (13) or to centrally-injected hypertonic saline (14), and the ensuing blood pressure elevation is greatly attenuated after chemical destruction of noradrenergic brain neurons with 6-hydroxydopamine (15) or electrolytic lesions of the anteroventral-third ventricle region (16). But even though these studies all suggest some central dysfunction, peripheral mechanisms cannot be completely ignored since manipulation of dietary salt ultimately affects tissues other than those in the brain.

When hypertonic $\mathrm{NaCl}$ was chronically infused into the third cerebral ventricle (ICV) ${ }^{1}$ to restrict salt-loading to the brain, blood pressure became elevated while depressor and sympatho-inhibitory responses to anterior hypothalamic stimulation were reduced (17). Because the anterior hypothalamus regulates baroreceptor reflexes $(18,19)$, it seemed logical to expect that chronic ICV infusions of hypertonic $\mathrm{NaCl}$ would also alter baroreflex responses to changes in blood pressure. Accordingly, we compared reflex heart rate and renal nerve responses to phenylephrine and sodium nitroprusside in rats that had been chronically infused ICV with either hypertonic $\mathrm{NaCl}$ or artificial cerebrospinal fluid (CSF) alone. Upon finding that reflex chronotropic responses were attenuated by hypertonic $\mathrm{NaCl}$, additional experiments were done to determine whether baroreflex dysfunction leads to or results from the attendant hypertension.

\section{Methods}

Experiments were done on 54 8-wk old male Sprague-Dawley rats purchased from SASCO Inc., Omaha, NE. An osmotic minipump was implanted into each rat for chronic infusion ICV of artificial CSF alone or of $0.8 \mathrm{M} \mathrm{NaCl}$ in artificial CSF. Due to various technical difficulties (e.g., pump malfunction, catheter failure, or inability to obtain CSF samples), 14 rats were discarded so that results finally compiled were from 40 rats that were used as follows: 14 for baroreflex testing while anesthetized, 9 for electrolyte measurements, and 17 for baroreflex testing while awake.

Preparing rats for chronic intracerebroventricular infusion. Each rat was anesthetized with sodium pentobarbital $(4 \mathrm{mg} / 100 \mathrm{~g}$ i.p.) and a cannula consisting of 26-gauge stainless steel tubing $(1.7 \mathrm{~cm}$ long bent midpoint at a right angle) was inserted ICV at stereotaxic coordinates: anteroposterior 3.0, lateral 0 , and dorsoventral -1.3 (20). The saggital sinus was punctured with a sharp needle so that bleeding could be controlled by pressing on the point of entry after insertion of the cannula. An osmotic minipump (model 2ML2, Alza Corp., Palo Alto, CA) was then implanted subcutaneously in the intracapsular region and connected through Teflon tubing to the ICV cannula. Procaine

1. Abbreviations used in this paper: CSF, cerebrospinal fluid; ICV, intracerebroventricular. penicillin $\mathrm{G}, 60,000$ unit IM, was given routinely to prevent postoperative infection.

Osmotic minipumps were filled with $2.3 \mathrm{ml}$ of either artificial CSF or $0.8 \mathrm{M} \mathrm{NaCl}$, and at a mean pumping rate of $5.62 \pm 0.21 \mu \mathrm{l} / \mathrm{h}$ would have an estimated pumping duration of $411 \mathrm{~h}$ or $17 \mathrm{~d}$. An artificial CSF consisting of Elliot's B solution (21) was used as the solvent for all ICV infusions. Each $\mathrm{ml}$ of this solution contained $7.3 \mathrm{mg}$ sodium chloride, $1.9 \mathrm{mg}$ sodium bicarbonate, $0.8 \mathrm{mg}$ dextrose, $0.3 \mathrm{mg}$ magnesium chloride, $0.3 \mathrm{mg}$ potassium chloride, $0.2 \mathrm{mg}$ calcium chloride, $0.2 \mathrm{mg}$ sodium phosphate, and $0.1 \mu \mathrm{g}$ phenolsulfonaphthalein.

Cardiovascular and sympathetic responses to phenylephrine or sodium nitroprusside in anesthetized rats. $11 \mathrm{~d}$ after minipump implantation, each rat was reanesthetized with methoxyflurane (Metofane by inhalation) to allow insertion of three catheters as follows: into the lower abdominal aorta for recording blood pressure, into a femoral vein for inducing further anesthesia through injection of $\alpha$-chloralose $(7 \mathrm{mg} / 100 \mathrm{~g}$ i.v.), and into a jugular vein for drug infusions. Phasic aortic pressure, heart rate, and sympathetic nerve activity were recorded continuously during slow intravenous infusions first of phenylephrine and then of sodium nitroprusside. Doses $(\mathrm{ng} / 100 \mathrm{~g}$ per min) ranging from 208 to 1,248 for phenylephrine, and from 208 to 1,040 for sodium nitroprusside were tested in preliminary experiments, and then infusion rates were selected that would either increase or lower mean blood pressure by $\sim 35 \mathrm{mmHg}$ within $60 \mathrm{~s}$. Final doses selected were $832 \mathrm{ng} / 100 \mathrm{~g}$ per min for phenylephrine and $624 \mathrm{ng} / 100 \mathrm{~g}$ per min for sodium nitroprusside. For each infusion a total volume of $20.8 \mu \mathrm{l}$ was delivered in $1 \mathrm{~min}$ by using a syringe pump. A recovery period of 20-30 min was always allowed between successive infusions. After nitroprusside infusion, bilateral sinoaortic denervation was performed as described by Krieger (22). Baroreceptor fibers from the aortic arch were eliminated by resecting the superior laryngeal nerves and sympathetic trunks together with the corresponding neurovascular sheaths. To denervate the carotid sinus, the bifurcation and adjacent carotid branches were stripped of connective tissues and painted with 10\% phenol. Both drug infusions were then repeated.

Pulsatile arterial pressure was recorded by connecting the aortic catheter through Tygon tubing to a low-volume-displacement pressure transducer (P23Gb, Statham Instruments, Inc., Oxnard, CA). Heart rates were monitored simultaneously by triggering a biotachometer with the phasic signal from the transducer. To analyze reflex changes in heart rate during drug infusions, pulse interval in milliseconds was determined by averaging five successive pulses (i.e., using the phasic pressure signal recorded at a speed of $2.5 \mathrm{~cm} / \mathrm{s}$, the distance required for five successive pulses was measured and then divided by five).

Renal nerve activity was recorded by placing the larger nerve bundle in the left renal pedicle (located between the artery and vein) over a bipolar platinum electrode (uninsulated tips $1 \mathrm{~mm}$ apart). Nerves and electrode tips were immersed in mineral oil. Spike potentials were amplified (P15AC amplifier, Grass Instrument Co., Quincy, MA) and recorded continuously on magnetic tapes, which were later played back into an amplitude analyzer (Frederick Haer and Co., Inc., Brunswick, ME) to convert individual spikes into uniform pulses (23). Number of individual pulses per second was counted with a rate analyzer whose output was recorded as a histogram on a thermalwriting recorder.

Sampling and measurement of CSF and serum electrolytes. After $11 \mathrm{~d}$ of chronic ICV infusion, 13 rats were anesthetized with sodium pentobarbital, $4 \mathrm{mg} / 100 \mathrm{~g}$ i.p., and an aortic catheter was inserted for blood sampling. Each rat was placed in a stereotaxic apparatus with the earbars serving as a fulcrum to tilt the head down at a $10^{\circ}$ angle. 
The cisterna magna was exposed through a dorsal midline incision by deflecting the muscle layer over the occiput. A 24-gauge needle connected to PE-50 polyethylene tubing was then inserted between the occiput and dorsal spine of the atlas, and 30-100 $\mu$ l samples of clear CSF were collected in nine rats. Serum samples were from $0.5-\mathrm{ml}$ aliquots of arterial blood obtained from the aortic catheter. Sodium and potassium concentrations were determined in all CSF and serum samples by using a flame photometer (Beckman Instruments Inc., Fullerton, CA).

Repeated recording of cardiovascular responses to phenylephrine in awake rats. At the same time that osmotic minipumps were implanted in 17 rats (eight infused with artificial CSF, and nine infused with 0.8 $\mathrm{M} \mathrm{NaCl}$ ), indwelling catheters were also inserted into a femoral vein and the lower abdominal aorta, and after closing all skin incisions with 9-mm stainless steel clips (Clay Adams, Div. of Becton-Dickinson $\&$ Co., Parsippany, NJ), the outer ends of both catheters were exteriorized at the nape of the neck. Chronic ICV infusions were then started, and on days 2 and 9 each awake rat was placed in a round open-topped cage and phasic aortic pressure was recorded continuously while graded doses of phenylephrine, $50-600 \mathrm{ng} / 100 \mathrm{~g}$, were injected intravenously to induce varying degrees of reflex bradycardia. Data obtained for phenylephrine-induced changes in mean aortic pressure and pulse interval were used to calculate slopes for assessing baroreflex sensitivity.

Drugs and statistics. Drugs used were phenylephrine hydrochloride and sodium nitroprusside, with doses expressed in terms of the respective salts $/ 100 \mathrm{~g}$ body weight. Data expressed as averages \pm SEM were analyzed using a two-way analysis of variance (24), and for F-ratios, with $P \leq 0.05$, Duncan's multiple range test (25) was applied to determine significance of differences between pairs of means. An analysis of covariance using program BMDP2V (26) was performed to examine reflex responses to infused drugs such that with mean aortic pressure as the covariant variable, means for changes in pulse interval or renal nerve firing were adjusted, and these were then compared using Duncan's multiple range test. As indices of reflex sensitivity, coefficients for linear regression were calculated for each rat by the method of least squares, and resulting slopes for the two rat groups were compared using the nonparametric Mann-Whitney U-test for independent samples (24). Regression coefficients obtained from each rat group before and after sinoaortic denervation were compared using the Wilcoxon test for dependent samples (24).

\section{Results}

Reflex heart rate and renal nerve responses to intravenouslyinfused drugs in anesthetized rats. As shown previously (17), continuous ICV infusion of $0.8 \mathrm{M} \mathrm{NaCl}$ in artificial CSF elevated blood pressure without affecting heart rate. When the rats were anesthetized with $\alpha$-chloralose on day 11 , systolic and mean pressures recorded from indwelling aortic catheters were consistently higher in $\mathrm{NaCl}$-infused than in control rats. Systolic pressures $(\mathrm{mmHg} \pm \mathrm{SEM})$ averaged $120 \pm 3$ in the controls and $132 \pm 3$ in $\mathrm{NaCl}$-infused rats; corresponding values for mean pressure were $106 \pm 2$ and $116 \pm 3$, respectively $(P$ $<0.05$ for both comparisons). On the other hand, differences in either heart rate beats per minute $(324 \pm 12$ vs. $345 \pm 11)$ or diastolic pressure $(92 \pm 3$ vs. $100 \pm 3)$ were not significant.

Progressive elevation of aortic blood pressure produced by intravenous infusion of phenylephrine was consistently accom-

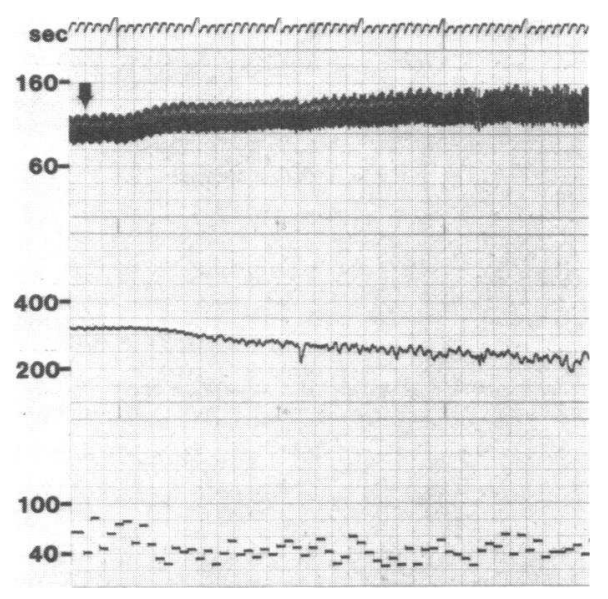

Figure 1. Cardiovascular and sympathetic nerve effects of phenylephrine in a chloralose-anesthetized rat that had been infused with artificial CSF alone. Tracings from top to bottom of phasic aortic pressure ( $\mathrm{mmHg}$ ), heart rate (beats per minute), and histogram showing frequency of sympathetic nerve firing (spikes/s). Arrow indicates onset of phenylephrine $(832 \mathrm{ng} / 100 \mathrm{~g}$ per min i.v.) infusion. Chart speed is $2.5 \mathrm{~mm} / \mathrm{s}$.

panied by reflex bradycardia and diminished renal nerve firing (Fig. 1). Blood pressure increases during the 1-min infusion period in both rat groups ranged from 3 to $30 \mathrm{mmHg}$, and within this range, magnitude of reflex decreases in heart rate and renal nerve firing were directly proportional to the size of the pressor response. Because initial base lines varied widely from rat to rat, data for renal nerve firing were expressed not only as absolute units but also as percent changes (Fig. 2). Magnitude of systemic pressor responses as well as of attendant decreases in frequency of sympathetic nerve firing, whether expressed as absolute or percent changes, was almost equal in both rat groups. Yet reflex bradycardia was more pronounced (i.e., pulse intervals were longer) in control rats than in those that had been infused ICV with $0.8 \mathrm{M} \mathrm{NaCl}$; during the last $50 \mathrm{~s}$ of phenylephrine infusion, pulse intervals were significantly longer in control than in $\mathrm{NaCl}$-infused rats (Fig. 3). Opposite reflex responses of tachycardia and accelerated renal nerve firing also occurred consistently in the same rats when aortic blood pressure was lowered by subsequent intravenous infusion of sodium nitroprusside (Fig. 4). Magnitude of both reflex responses was generally proportional to that of the fall in blood pressure, but while increases in renal nerve firing were almost the same in both rat groups (Fig. 2), $\mathrm{NaCl}$-infused rats had significantly larger depressor responses and smaller decreases in pulse interval (Fig. 3) than the controls.

When regression coefficients were calculated for each rat, whereas the slopes for reflex changes in heart interval were significantly lower for either phenylephrine or sodium nitroprusside in $\mathrm{NaCl}$-infused than in control rats, none of the corresponding differences between slopes for reflex changes in renal nerve firing was significant (Table I). Hence, as was 


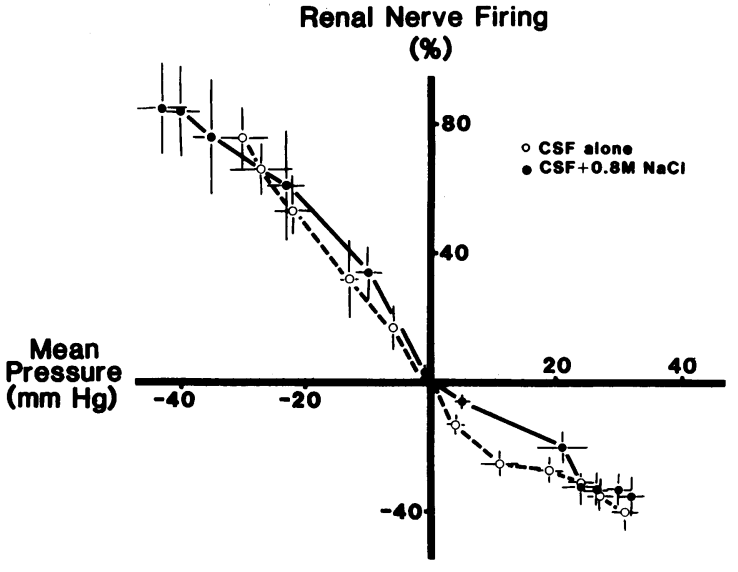

Figure 2. Reflex changes in renal nerve firing plotted against either increases in mean aortic pressure during intravenous infusions of phenylephrine (right half) or decreases in mean aortic pressure produced by similar infusions of sodium nitroprusside (left half).

previously indicated by examining either the raw data or the adjusted means obtained with the analysis of covariance, the regression coefficients for both phenylephrine and sodium nitroprusside clearly showed that in $\mathrm{NaCl}$-infused rats, reflex changes in heart rate were attenuated while attendant changes in renal nerve firing were unaffected.

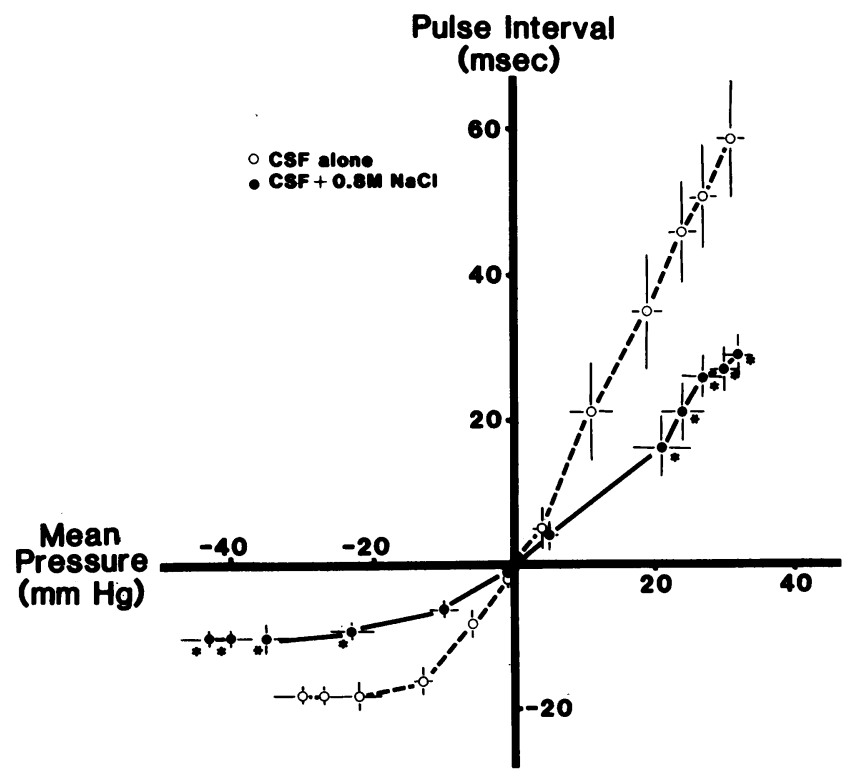

Figure 3. Reflex changes in pulse interval plotted against either increases in mean aortic pressure during intravenous infusions of phenylephrine (right half) or decreases in mean aortic pressure produced by similar infusions of sodium nitroprusside (left half). Asterisks indicate significant differences $(P<0.01)$ upon comparison with the corresponding average for control rats using an analysis of covariance.

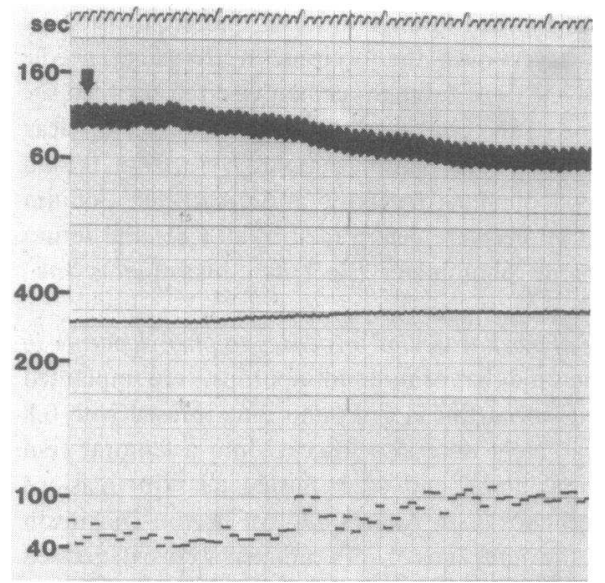

Figure 4. Cardiovascular and sympathetic nerve effects of sodium nitroprusside (624 $\mathrm{ng} / 100 \mathrm{~g}$ per min i.v.) from the same rat shown in Fig. 1.

Abolition of reflex chronotropic responses after sino-aortic denervation. When drug infusions were repeated after sinoaortic denervation, in all rats magnitude of both pressor responses to phenylephrine and depressor responses to nitroprusside was slightly enhanced, but reflex changes in both pulse interval and renal nerve firing were markedly reduced (Table II). These results indicate that all heart rate and renal nerve responses to both drugs (i.e., comparing regression coefficients for intact rats against those after sinoaortic denervation in Table I) were induced reflexly since they were either abolished or markedly reduced after sinoaortic denervation.

Elevated CSF sodium concentration in NaCl-infused rats. Sodium concentration on day 11 of ICV infusion was almost the same in serum samples from both rat groups, but that in CSF was significantly higher in $\mathrm{NaCl}$-infused than in control rats (Table III). By contrast, potassium concentrations in both serum and CSF did not differ.

Which comes first during ICV infusion of hypertonic $\mathrm{NaCl}$ : baroreflex impairment or hypertension? Since this question could not be answered from results obtained in anesthetized rats that were already hypertensive when baroreflex impairment was discovered, additional experiments were done to allow repeated baroreflex testing during the ICV infusions. Chronically implanted venous and aortic catheters were used to record cardiovascular responses to graded doses of phenylephrine while the rats were awake on days 2 and 9 during the ICV infusions. On day 2, there were no significant differences in base lines for aortic pressure or heart rate (Table IV), but even though pressor responses elicited by subsequent intravenous injections of phenylephrine were almost equal in both groups, reflex bradycardia was already appreciably lower in $\mathrm{NaCl}$ infused than in control rats. For doses of 400 and $600 \mathrm{ng} / 100$ g, group differences in pulse interval were statistically significant, and the corresponding slope for reflex bradycardia was also significantly lower in the $\mathrm{NaCl}$-infused than in the control 
Table I. Regression Coefficients Obtained from Chloralose-Anesthetized Rats Before and After Sinoaortic Denervation in Response to Intravenous Infusions of Phenylephrine or Sodium Nitroprusside

\begin{tabular}{|c|c|c|c|c|}
\hline \multirow{3}{*}{$\begin{array}{l}\text { Sinoaortic } \\
\text { innervation }\end{array}$} & \multicolumn{4}{|l|}{ Rat groups } \\
\hline & \multicolumn{2}{|l|}{ CSF alone } & \multicolumn{2}{|l|}{$0.8 \mathrm{M} \mathrm{NaCl}$} \\
\hline & Phenylephrine & Nitroprusside & Phenylephrine & Nitroprusside \\
\hline \multicolumn{5}{|c|}{ Slopes of pulse interval ( $\Delta m s / \Delta m m H g)$} \\
\hline Intact & $\begin{array}{c}1.89 \pm 0.20 \\
(r=0.98)\end{array}$ & $\begin{array}{c}0.64 \pm 0.11 \\
(r=0.89)\end{array}$ & $\begin{array}{l}0.93 \pm 0.11^{*} \\
(r=0.96)\end{array}$ & $\begin{array}{l}0.24 \pm 0.03^{*} \\
(r=0.89)\end{array}$ \\
\hline Denervated & $\begin{array}{l}-0.18 \pm 0.07 \ddagger \\
(r=-0.72)\end{array}$ & $\begin{array}{l}-0.03 \pm 0.02 \ddagger \\
(r=-0.37)\end{array}$ & $\begin{array}{l}-0.21 \pm 0.09 \ddagger \\
(r=-0.81)\end{array}$ & $\begin{array}{l}-0.02 \pm 0.02 \ddagger \\
(r=-0.21)\end{array}$ \\
\hline \multicolumn{5}{|c|}{ Slopes of renal nerve activity $(\Delta \% / \Delta m m H g$ ) } \\
\hline Intact & $\begin{array}{l}-1.26 \pm 0.30 \\
(r=-0.91)\end{array}$ & $\begin{array}{l}-3.12 \pm 0.71 \\
(r=-0.93)\end{array}$ & $\begin{array}{c}-1.14 \pm 0.23 \\
(r=-0.90)\end{array}$ & $\begin{array}{c}-2.00 \pm 0.36 \\
(r=-0.94)\end{array}$ \\
\hline Denervated & $\begin{array}{l}-0.03 \pm 0.06 \ddagger \\
(r=-0.06)\end{array}$ & $\begin{array}{l}-0.06 \pm 0.12 \ddagger \\
(r=-0.22)\end{array}$ & $\begin{array}{l}0.08 \pm 0.09 \ddagger \\
(r=0.03)\end{array}$ & $\begin{array}{l}0.07 \pm 0.09 \ddagger \\
(r=0.28)\end{array}$ \\
\hline
\end{tabular}

${ }^{*} P<0.05$, compared with corresponding average for controls infused with CSF alone using the Mann-Whitney U-test. $\quad P<0.05$, compared with corresponding average before denervation using the Wilcoxon sign test.

group (Table $\mathrm{V}$ ). When the same rats were tested again on day 9, all aortic pressures were higher in $\mathrm{NaCl}$-infused rats (Table IV), and despite equal pressor responses, inhibition of reflex bradycardia was more pronounced since even responses to 100 and $200 \mathrm{ng} / 100 \mathrm{~g}$ doses of phenylephrine were significantly reduced (Table $\mathrm{V}$ ). Hence, by showing that diminution of reflex bradycardia had already occurred on day 2 while the $\mathrm{NaCl}$-infused rats were still normotensive, these results clearly indicate that during $\mathrm{ICV}$, infusion of hypertonic $\mathrm{NaCl}$ baroreflexes became inhibited even before hypertension developed.

\section{Discussion}

To determine whether salt-induced central neurogenic mechanisms would be easier to demonstrate when exposure to excess salt is limited to the brain, we used osmotic minipumps to chronically infuse hypertonic $\mathrm{NaCl} \mathrm{ICV}$ in awake rats. Based on our previous finding that blood pressure became progressively elevated while responses to anterior hypothalamic stimulation were reduced (17), it seemed logical to expect that baroreflex sensitivity would also be affected. In accord with that expectation, we found baroreflex sensitivity reduced in rats that had been chronically infused ICV with hypertonic $\mathrm{NaCl}$. Upon intravenously infusing test drugs in anesthetized rats, reflex bradycardia elicited during pressor responses to phenylephrine was more prominent than the reflex tachycardia elicited during depressor responses to sodium nitroprusside (Fig. 2). Nonetheless, changes in heart rate induced reflexly with either drug were consistently more pronounced in control than in $\mathrm{NaCl}$-infused rats, and since corresponding regression coefficients also differed significantly (Table I), then our results indeed suggest that reflex chronotropic responses had been attenuated. Subsequently, attenuation of phenylephrine-induced reflex bradycardia in awake rats during day 2 of chronic ICV infusion of $\mathrm{NaCl}$ was shown to occur (Table $\mathrm{V}$ ) even before hypertension developed (Table IV).

Despite the unequivocal demonstration that chronic ICV infusion of hypertonic $\mathrm{NaCl}$ attenuated drug-induced chronotropic reflex responses, a similar conclusion cannot be reached regarding associated changes in renal nerve firing. Even though the reflex origin of both heart rate and renal nerve responses was verified by their abolition after sinoaortic denervation, inasmuch as renal nerve activity varied widely from rat to rat, SDs in both rat groups were quite large, and none of the differences in corresponding regression coefficients was significant (Tables I and II). The absence of appreciable differences between control and $\mathrm{NaCl}$-infused rats could mean that reflex changes in renal nerve firing, unlike reflex changes in heart rate, were unaffected by centrally-infused hypertonic $\mathrm{NaCl}$. If so, then selective inhibition of one response without alteration of the other may reflect specificity in baroreflex regulation as has been shown by Ricksten and Thoren (27) in spontaneously hypertensive rats, and by Guo et al. (4) in renal hypertensive rabbits. Alternatively, since spike potentials could be recorded only from intact renal nerves (because the renal nerves were very small, they were left intact to keep recording electrodes 
Table II. Time-Course of Changes in Mean Aortic Pressure, Pulse Interval, and Renal Nerve Firing during Intravenous Drug Infusions After Sinoaortic Denervation in Chloralose-Anesthetized Rats*

\begin{tabular}{|c|c|c|c|c|c|c|}
\hline \multirow[b]{2}{*}{ Rat group } & \multicolumn{6}{|c|}{ Time $(s)$ during drug infusion } \\
\hline & 10 & 20 & 30 & 40 & 50 & 60 \\
\hline \multicolumn{7}{|l|}{ Phenylephrine } \\
\hline \multicolumn{7}{|c|}{ Mean aortic pressure $(\mathrm{mmHg})$} \\
\hline CSF alone & $2 \pm 1$ & $13 \pm 2$ & $25 \pm 2$ & $32 \pm 2$ & $37 \pm 3$ & $39 \pm 5$ \\
\hline $0.8 \mathrm{M} \mathrm{NaCl}$ & $3 \pm 1$ & $16 \pm 4$ & $29 \pm 5$ & $35 \pm 5$ & $39 \pm 5$ & $41 \pm 4$ \\
\hline \multicolumn{7}{|c|}{ Pulse interval ( $m s)$} \\
\hline CSF alone & $-1 \pm 1$ & $-2 \pm 1$ & $-3 \pm 2$ & $-5 \pm 2$ & $-6 \pm 2$ & $-8 \pm 3$ \\
\hline $0.8 \mathrm{M} \mathrm{NaCl}$ & $0 \pm 1$ & $-1 \pm 1$ & $-4 \pm 3$ & $-5 \pm 4$ & $-7 \pm 4$ & $-9 \pm 4$ \\
\hline \multicolumn{7}{|c|}{ Renal nerve firing (spikes/s) } \\
\hline CSF alone & $0 \pm 1$ & $-1 \pm 3$ & $-4 \pm 3$ & $-2 \pm 2$ & $-1 \pm 1$ & $0 \pm 1$ \\
\hline $0.8 \mathrm{M} \mathrm{NaCl}$ & $1 \pm 1$ & $-1 \pm 2$ & $2 \pm 2$ & $2 \pm 2$ & $3 \pm 2$ & $1 \pm 3$ \\
\hline \multicolumn{7}{|c|}{ Renal nerve firing (\%) } \\
\hline CSF alone & $-2 \pm 2$ & $-3 \pm 4$ & $-6 \pm 4$ & $-2 \pm 3$ & $-2 \pm 3$ & $-1 \pm 3$ \\
\hline $0.8 \mathrm{M} \mathrm{NaCl}$ & $1 \pm 1$ & $-1 \pm 3$ & $3 \pm 3$ & $4 \pm 4$ & $5 \pm 4$ & $3 \pm 5$ \\
\hline \multicolumn{7}{|l|}{ Nitroprusside } \\
\hline \multicolumn{7}{|c|}{ Mean aortic pressure $(\mathrm{mmHg})$} \\
\hline CSF alone & $-1 \pm 1$ & $-9 \pm 2$ & $-28 \pm 5$ & $-41 \pm 6$ & $-51 \pm 4$ & $-56 \pm 4$ \\
\hline $0.8 \mathrm{M} \mathrm{NaCl}$ & $-1 \pm 1$ & $-14 \pm 4$ & $-29 \pm 7$ & $-41 \pm 5$ & $-48 \pm 4$ & $-53 \pm 4$ \\
\hline \multicolumn{7}{|c|}{ Pulse interval (ms) } \\
\hline CSF alone & $1 \pm 1$ & $0 \pm 1$ & $2 \pm 1$ & $2 \pm 1$ & $2 \pm 1$ & $2 \pm 1$ \\
\hline $0.8 \mathrm{M} \mathrm{NaCl}$ & $0 \pm 1$ & $1 \pm 0$ & $1 \pm 0$ & $1 \pm 1$ & $1 \pm 1$ & $1 \pm 1$ \\
\hline \multicolumn{7}{|c|}{ Renal nerve firing (spikes/s) } \\
\hline CSF alone & $-1 \pm 1$ & $1 \pm 2$ & $2 \pm 4$ & $2 \pm 3$ & $2 \pm 4$ & $3 \pm 3$ \\
\hline $0.8 \mathrm{M} \mathrm{NaCl}$ & $1 \pm 1$ & $0 \pm 2$ & $-2 \pm 1$ & $0 \pm 1$ & $2 \pm 3$ & $3 \pm 3$ \\
\hline \multicolumn{7}{|c|}{ Renal nerve firing (\%) } \\
\hline CSF alone & $-2 \pm 2$ & $3 \pm 3$ & $2 \pm 6$ & $4 \pm 6$ & $4 \pm 7$ & $5 \pm 6$ \\
\hline $0.8 \mathrm{M} \mathrm{NaCl}$ & $1 \pm 2$ & $-1 \pm 3$ & $-4 \pm 4$ & $-1 \pm 2$ & $4 \pm 4$ & $5 \pm 5$ \\
\hline
\end{tabular}

* Data are changes from base lines of: $128 \pm 5 \mathrm{mmHg}$ for mean pressure, $177 \pm 7 \mathrm{~ms}$ for pulse interval, and $64 \pm 5$ spikes/s for nerve firing in control rats; and of $133 \pm 5 \mathrm{mmHg}, 172 \pm 3 \mathrm{~ms}$, and $64 \pm 4$ spikes/s, respectively, in $\mathrm{NaCl}$-infused rats.

Table III. Electrolyte Concentrations (meq/liter) in CSF and Serum Samples on Day 11 of Chronic ICV Infusion in Pentobarbital-Anesthetized Rats

\begin{tabular}{llllll}
\hline & CSF & & & \multicolumn{2}{l}{ Serum } \\
\cline { 2 - 3 } \cline { 5 - 6 } Rat group & Sodium & Potassium & & Sodium & Potassium \\
\hline CSF alone & $144.8 \pm 0.8$ & $3.3 \pm 0.2$ & & $139.4 \pm 1.0$ & $4.5 \pm 0.1$ \\
$0.8 \mathrm{M} \mathrm{NaCl}$ & $152.2 \pm 1.9^{*}$ & $3.3 \pm 0.3$ & & $134.6 \pm 1.8$ & $4.4 \pm 0.1$ \\
\hline
\end{tabular}

* $P<0.05$, as compared with average for controls infused with CSF alone using an independent $t$ test. in place), afferent as well as efferent signals may have been recorded simultaneously from the same nerve bundle.

Bolus injections were compared with infusions by Coleman (28) for intravenous administration of equipressor doses of angiotensin, methoxamine, or phenylephrine in conscious rats. He used ratios, calculated by dividing the maximum reduction in heart rate by the maximum increase in mean blood pressure, to quantify reflex activity. Slightly larger ratios were always obtained for each drug by infusion than by injection, yet he concluded that either route can be used for testing heart rate reflexes. In testing anesthetized rats we opted for infusions because injections produce short-lived blood pressure effects 
Table IV. Base Lines for Aortic Pressure ( $\mathrm{mmHg}$ ) and Heart Rate (beats per minute) During Chronic ICV Infusions in Awake Rats

\begin{tabular}{|c|c|c|c|c|c|}
\hline \multirow{2}{*}{$\begin{array}{l}\text { Days of } \\
\text { infusion }\end{array}$} & \multirow[b]{2}{*}{ Rat groups } & \multicolumn{3}{|c|}{ Aortic pressure } & \multirow[b]{2}{*}{ Heart rate } \\
\hline & & Systolic & Mean & Diastolic & \\
\hline \multirow[t]{2}{*}{2} & CSF alone & $137 \pm 3$ & $105 \pm 2$ & $90 \pm 3$ & $376 \pm 15$ \\
\hline & $0.8 \mathrm{M} \mathrm{NaCl}$ & $136 \pm 3$ & $104 \pm 2$ & $88 \pm 2$ & $355 \pm 6$ \\
\hline \multirow[t]{2}{*}{9} & CSF alone & $135 \pm 3$ & $105 \pm 3$ & $89 \pm 3$ & $369 \pm 6$ \\
\hline & $0.8 \mathrm{M} \mathrm{NaCl}$ & $150 \pm 3^{*}$ & $117 \pm 2^{*}$ & $100 \pm 3^{*}$ & $376 \pm 7$ \\
\hline
\end{tabular}

* $P<0.01$, compared either with corresponding average for the same group on day 2 or with corresponding average for the control group on day 9.

that elicit equally transient reflex changes in heart rate or renal nerve firing. By slowly infusing the same test drugs, blood pressure effects occurred much more gradually, and attendant reflex changes could be determined at various pressure levels during a single infusion (see Figs. 1 and 4). Conversely, in

Table V. Cardiovascular Responses to

Phenylephrine Recorded on Two Separate Days During Chronic ICV Infusion of Awake Rats

\begin{tabular}{|c|c|c|c|c|c|}
\hline \multirow[b]{2}{*}{ Rat groups } & \multicolumn{5}{|c|}{ Phenylephrine doses ( $n g / 100 \mathrm{~g}$ i.v.) } \\
\hline & 50 & 100 & 200 & 400 & 600 \\
\hline \multicolumn{6}{|c|}{ Day 2 of ICV infusion } \\
\hline \multicolumn{6}{|c|}{$\Delta$ Mean aortic pressure $(\mathrm{mmHg})$} \\
\hline CSF alone & $15 \pm 2$ & $27 \pm 2$ & $38 \pm 2$ & $47 \pm 2$ & $56 \pm 2$ \\
\hline $0.8 \mathrm{M} \mathrm{NaCl}$ & $13 \pm 2$ & $23 \pm 2$ & $36 \pm 2$ & $51 \pm 2$ & $57 \pm 2$ \\
\hline \multicolumn{6}{|c|}{$\Delta$ Pulse interval $(\mathrm{ms})$} \\
\hline CSF alone & $15 \pm 3$ & $25 \pm 3$ & $35 \pm 3$ & $53 \pm 3$ & $66 \pm 5$ \\
\hline $0.8 \mathrm{M} \mathrm{NaCl}$ & $13 \pm 2$ & $21 \pm 2$ & $33 \pm 4$ & $41 \pm 4^{*}$ & $51 \pm 6^{*}$ \\
\hline \multicolumn{6}{|c|}{ Baroreflex slope $(\Delta m s / \Delta m m H g)$} \\
\hline CSF alone & $1.25 \pm 0$. & $r=0.95$ & & & \\
\hline $0.8 \mathrm{M} \mathrm{NaCl}$ & $0.82 \pm 0$ & $r=0.96$ & & & \\
\hline \multicolumn{6}{|c|}{ Day 9 of ICV infusion } \\
\hline \multicolumn{6}{|c|}{$\Delta$ Mean aortic pressure $(\mathrm{mmHg})$} \\
\hline CSF alone & $16 \pm 2$ & $28 \pm 3$ & $40 \pm 4$ & $47 \pm 3$ & $53 \pm 4$ \\
\hline $0.8 \mathrm{NaCl}$ & $14 \pm 1$ & $25 \pm 3$ & $36 \pm 2$ & $49 \pm 2$ & $57 \pm 2$ \\
\hline \multicolumn{6}{|c|}{$\Delta$ pulse interval $(m s)$} \\
\hline CSF alone & $17 \pm 1$ & $30 \pm 2$ & $43 \pm 4$ & $57 \pm 3$ & $72 \pm 5$ \\
\hline $0.8 \mathrm{M} \mathrm{NaCl}$ & $10 \pm 1$ & $16 \pm 2^{*}$ & $23 \pm 3^{*}$ & $33 \pm 4^{*}$ & $41 \pm 5^{*}$ \\
\hline \multicolumn{6}{|c|}{ Baroreflex slope ( $\Delta m s / \Delta m m H g$ ) } \\
\hline CSF alone & $1.41 \pm 0.0$ & $r=0.95$ & & & \\
\hline $0.8 \mathrm{M} \mathrm{NaCl}$ & $0.67 \pm 0.0$ & $r=0.95$ & & & \\
\hline
\end{tabular}

* $P<0.05$, compared with corresponding average for controls infused with CSF alone using Duncan's multiple range test.

$\ddagger P<0.05$, compared with corresponding slope for the control group using the Mann-Whitney U-test. awake rats we used bolus injections of phenylephrine (Table V) solely to avoid unduly prolonged effects and minimize unnecessary manipulation.

What happened in the brain as hypertonic $\mathrm{NaCl}$ was slowly infused ICV for several days is conjectural. In rats, as in other animal species, CSF secreted at the choroid plexus circulates from the ventricles to the subarachnoid space, whence it is absorbed through the arachnoid villi. Rat CSF contains about $148 \mathrm{mEq} / 1$ of sodium (29), and is secreted at a rate of 2.2 $\mu \mathrm{g} / \mathrm{min}(30)$. Since intravenously injected ${ }^{24} \mathrm{Na}$ crosses the choroid plexus readily and diffuses rapidly from CSF into brain (31), hypertonic $\mathrm{NaCl}$ probably behaves similarly during ICV infusion. After $11 \mathrm{~d}$ of infusing $0.8 \mathrm{M} \mathrm{NaCl}$ at a rate of $5.6 \mu \mathrm{l} / \mathrm{h}$, we found sodium concentrations unaffected in serum but appreciably elevated in CSF obtained from the cisterna magna (Table III). Peripheral leakage of ICV-infused hypertonic $\mathrm{NaCl}$ is therefore unlikely because serum sodium concentration was unaltered. On the other hand, while CSF sodium was elevated to just slightly above the concentration considered normal for anesthetized rats (29), it may have sufficed to alter hypothalamic neuronal activity (i.e., iontophoretic application of sodium has recently been reported to increase firing of various hypothalamic neurons; [32]) and this in turn could have attenuated baroreflex heart rate responses. Whether hypertonic $\mathrm{NaCl}$ was acting here as a chemical stimulus on osmotic or on sodium receptors (33) remains unresolved. Although a specific action on sodium receptors seems more likely because we found pressor responses to short-term ICV infusions of hypertonic $\mathrm{NaCl}$ accompanied by increased sympathetic nerve firing while other hypertonic solutions were ineffective (34), similar comparisons involving chronic infusions have yet to be made.

In trying to visualize where hypertonic $\mathrm{NaCl}$ was most likely to act relative to the infusion site, brain areas in the immediate vicinity of the third ventricle, referred to as the anteroventral third cerebral ventricle region (35), would rank among the prime suspects. Two separate neural pathways that could influence blood pressure regulation prominently have been identified with the anteroventral third cerebral ventricle region: one projects periventricularly through the anterior hypothalamus to the ventromedial hypothalamus, and the other courses through the medial forebrain bundle to converge with the first pathway in the ventromedial hypothalamus (36). In addition to descending hypothalamic pathways (37), abundant neural projections ascend from the nucleus tractus solitarii (which contain the secondary neurons in the baroreceptor reflex arc [38]) and buffer nerves to various hypothalamic areas including the anterior hypothalamus (39). If the anterior hypothalamus truly represents the rostral part of the forebrain loop responsible for integrating baroreflex activity, attenuation could therefore result from selective inhibition by ICV-infused $\mathrm{NaCl}$ of anterior hypothalamic neurons that normally decrease sympathetic activity. In view of the complex integration of central facilitatory and inhibitory mechanisms for blood pres- 
sure regulation, other components of the reflex arc could also be involved. Another logical explanation is that hypothalamic signals for baroreflex inhibition, instead of being neural, might be humoral. However, humoral mediation by either angiotensin or vasopressin seems unlikely because acute ICV infusions of $\mathrm{NaCl}$ lower plasma renin concentration (40), and although such infusions may increase vasopressin release (41), vasopressin enhances rather than inhibits baroreflex gain (42).

Baroreflex dysfunction usually occurs during both experimental and clinical hypertension, and previous evidence indicates that baroreceptor resetting occurs almost as soon as hypertension develops. Within 24 to $48 \mathrm{~h}$ after Krieger (43) made Wistar rats acutely hypertensive by aortic constriction, he found an upward displacement of pressure thresholds for aortic nerve firing, which signified that baroreceptor resetting already existed. On the other hand, baroreflex impairment does not always occur whenever rats become hypertensive. In two recent studies designed to assess interactions between baroreflexes and the posterior hypothalamus in spontaneously hypertensive rats, baroreceptor sensitivity was found diminished in one study (44), but unaltered in the other (45). Furthermore, despite the apparent similarity between our results and those obtained by Guo et al. (4) in renal hypertensive rabbits (i.e., selective impairment of baroreflex heart rate responses while sympathetic nerve responses were preserved), nerve activity was actually recorded from different sites since we used the renal nerves while they recorded from the lumbar sympathetic trunks. As they pointed out, what they observed cannot really be extrapolated to other sympathetic nerves since Thames and Gupta (46) have shown that in renal hypertensive rabbits, baroreflex regulation not only of heart rate but also of renal nerve activity was impaired even though attendant responses in aortic depressor nerve activity were preserved.

Perhaps more pertinent to alterations induced by salt loading are the studies of Gordon et al. (3), which showed that in Dahl salt-sensitive rats baroreflexes became impaired even before hypertension developed, thereby suggesting that baroreflex dysfunction precedes and as such could contribute to, rather than result from, the subsequent development of saltinduced hypertension. A similar sequence could not be established in the anesthetized rats we initially studied because they were already hypertensive when baroreflex impairment was discovered. However, our later experiments, in which reflex bradycardia to phenylephrine was recorded on days 2 and 9 while ICV infusions were being given in awake rats (Table V), clearly showed that reflex bradycardia was already inhibited even on day 2 when the $\mathrm{NaCl}$-infused rats were still normotensive (Table IV). Thus, our results may mean that even in rats without a genetic predisposition to develop hypertension, chronic ICV infusion of hypertonic $\mathrm{NaCl}$ can cause deficient baroreflex buffering that could eventually elevate blood pressure.

Though ICV infusions of hypertonic $\mathrm{NaCl}$ are never used clinically, CSF sodium levels occasionally become elevated in certain patients with essential hypertension classified as being "salt sensitive" (47). The elevation in CSF sodium levels found in salt-sensitive hypertensives maintained on high salt intake correlates significantly with changes in mean pressure, urinary sodium excretion, and plasma renin (48). Because plasma norepinephrine levels during high salt intake remain unaltered in salt-sensitive hypertensive patients but are reduced in normal subjects and "non-salt-sensitive" hypertensive patients (49), abnormal relationships between salt intake and sympathetic activity have been suggested. Our findings indicate that when such abnormal relationships are induced experimentally by infusing hypertonic $\mathrm{NaCl} \mathrm{ICV}$ into rats, anterior hypothalamic inhibition reduces baroreflex sensitivity, and the ensuing sympathetic hyperactivity results in hypertension.

\section{Acknowledgments}

This work was supported by research grant HL 14560 from the National Heart, Lung, and Blood Institute.

\section{References}

1. McCubbin, J. W., J. H. Green, and I. H. Page. 1956. Baroreceptor function in chronic renal hypertension. Circ. Res. 4:205-212.

2. Angell-James, J. E., M. J. George, and C. J. Peters. 1980. Baroreflex sensitivity in rabbits during the development of experimental renal hypertension and medial sclerosis. Clin. Exp. Hypertens. 2:321340.

3. Gordon, F. J., H. Matsuguchi, and A. L. Mark. 1981. Abnormal baroreflex control of heart rate in prehypertensive and hypertensive Dahl genetically salt-sensitive rats. Hypertension. 3(Suppl. I):135-141.

4. Guo, G. B., M. D. Thames, and F. M. Abboud. 1983. Arterial baroreflexes in renal hypertensive rabbits. Circ. Res. 53:223-234.

5. Bristow, J. D., A. J. Honour, G. W. Pickering, P. Sleight, and H. S. Smyth. 1969. Diminished baroreflex sensitivity in high blood pressure. Circulation. 39:48-54.

6. Korner, P. I., M. J. West, J. Shaw, and J. B. Uther. 1974. 'Steady-state' properties of the baroreceptor-heart rate reflex in essential hypertension in man. Clin. Exp. Pharmacol. Physiol. 1:65-76.

7. Takeshita, A., S. Tanaka, A. Kuroiwa, and M. Nakamura. 1975. Reduced baroreceptor sensitivity in borderline hypertension. Circulation. 51:738-742.

8. Sleight, P., M. J. West, P. I. Korner, J. R. Oliver, J. P. Chalmers, and J. L. Robinson. 1975. The action of clonidine on the baroreflex control of heart rate in conscious animals and man, and on single aortic baroreceptor discharge in the rabbit. Arch. Int. Pharmacodyn. Ther. 214:4-11.

9. Gonzalez, E. R., A. J. Krieger, and H. N. Sapru. 1983. Central resetting of baroreflex in the spontaneously hypertensive rat. Hypertension. 5:346-352.

10. Sasaki, S., and R. D. Buñag. 1983. Hypothalamic lesions abolish cardiovascular responses to chronic saline ingestion. Am. J. Physiol. 244:R751-R757.

11. Nakamura, K., M. Gerold, and H. Thoenen. 1971. Experimental hypertension of the rat: reciprocal changes of norepinephrine turnover in heart and brain-stem. Naunyn-Schmiedebergs Arch. Pharmakol. 268:125-139.

12. van Ameringen, M., J. de Champlain, and S. Imbeault. 1977. Participation of central noradrenergic neurons in experimental hypertension. Can. J. Physiol. Pharmacol. 55:1246-1251.

13. Buñag, R. D., J. Butterfield, and S. Sasaki. 1983. Hypothalamic 
pressor responses and salt-induced hypertension in Dahl rats. Hypertension. 5:460-467.

14. Ikeda, T., L. Tobian, J. Iwai, and P. Goossens. 1978. Central nervous system pressor responses in rats susceptible and resistant to sodium chloride hypertension. Clin. Sci. Mol. Med. 55:225s-227s.

15. Goto, A., T. Ikeda, L. Tobian, J. Iwai, and M. A. Johnson. 1981. Brain lesions in the paraventricular nuclei and catecholaminergic neurons minimize salt hypertension in Dahl salt-sensitive rats. Clin. Sci. (Lond.). 61:53s-55s.

16. Goto, A., M. Ganguli, L. Tobian, M. A. Johnson, and J. Iwai. 1982. Effect of an anteroventral third ventricle lesion on $\mathrm{NaCl}$ hypertension in Dahl salt-sensitive rats. Am. J. Physiol. 243:H614-H618.

17. Miyajima, E., and R. D. Buñag. 1984. Chronic cerebroventricular infusion of hypertonic sodium chloride elevates blood pressure in rats by reducing hypothalamic sympatho-inhibition. Circ. Res. 54:566575.

18. Hilton, S. M., and K. M. Spyer. 1971. Participation of the anterior hypothalamus in the baroreceptor reflex. J. Physiol. (Lond.). 218:271-293.

19. Spyer, K. M. 1972. Baroreceptor sensitive neurones in the anterior hypothalamus of the cat. J. Physiol. (Lond.). 224:245-257.

20. Pellegrino, L. J., A. A. Pellegrino, and A. J. Cushman. 1979. Stereotaxic Atlas of the Rat Brain. Appleton-Century-Crofts, East Norwalk, CT. 46-47.

21. Falcon, J. C., M. Ian Phillips, W. E. Hoffman, and M. J. Brody. 1978. Effects of intraventricular angiotensin II mediated by the sympathetic nervous system. Am. J. Physiol. 235:H392-H399.

22. Krieger, E. M. 1964. Neurogenic hypertension in the rat. Circ. Res. 15:511-521.

23. Takeda, K., and R. D. Buñag. 1978. Sympathetic hyperactivity during hypothalamic stimulation in spontaneously hypertensive rats. J. Clin. Invest. 62:642-648.

24. Bruning, J., and B. Kintz. 1977. Computational Handbook of Statistics. Scott, Foresman and Co., Glenview, IL. 24-27.

25. Duncan, D. B. 1955. Multiple range and multiple F tests. Biometrics. 11:1-42.

26. Dixon, W. B., and M. G. Brown. 1977. Biomedical Computing Programs. P Series. University of California Press, Berkeley, CA.

27. Ricksten, S. E., and P. Thoren. 1981. Reflex control of sympathetic nerve activity and heart rate from arterial baroreceptors in conscious spontaneously hypertensive rats. Clin. Sci. (Lond.). 61:169s$172 \mathrm{~s}$.

28. Coleman, T. G. 1980. Arterial baroreflex control of heart rate in the conscious rat. Am. J. Physiol. 238:H515-H520.

29. Reed, D. J., C. D. Withrow, and D. M. Woodbury. 1967. Electrolyte and acid-base parameters of rat cerebrospinal fluid. Exp. Brain Res. 3:212-219.

30. Cserr, H. 1965. Potassium exchange between cerebrospinal fluid, plasma, and brain. Am. J. Physiol. 209:1219-1226.

31. Katzman, R., and H. M. Pappius. 1973. Brain Electrolytes and Fluid Metabolism. Williams and Wilkins, Baltimore, MD. 75-110.

32. Mandelbrod, I., S. Feldman, and R. Werman. 1983. Mediobasal hypothalamic neurons are excited by the iontophoretic application of sodium. Brain Res. 273:35-44.

33. Thrasher, T. N., C. J. Brown, L. C. Keil, and D. J. Ramsay.
1980. Thirst and vasopressin release in the dog: an osmoreceptor or sodium receptor mechanism. Am. J. Physiol. 238:R333-R339.

34. Buñag, R. D., and E. Miyajima. 1984. Sympathetic hyperactivity elevates blood pressure during acute cerebroventricular infusions of hypertonic salt in rats. J. Cardiovasc. Pharmacol. In press.

35. Buggy, J., and A. K. Johnson. 1977. Preoptic-hypothalamic periventricular lesions: thirst deficits and hypernatremia. Am. J. Physiol. 233:R44-R52.

36. Hartle, D. K., and M. J. Brody. 1982. Hypothalamic vasomotor pathways mediating the development of hypertension in the rat. Hypertension. 4(Suppl. III):68-71.

37. Ciriello, J., and F. R. Calaresu. 1977. Descending hypothalamic pathways with cardiovascular function in the cat: a silver impregnation study. Exp. Neurol. 57:561-580.

38. Palkovits, M., and L. Zaborsky. 1977. Neuroanatomy of central cardiovascular control. Nucleus tractus solitarii: afferent and efferent neuronal connections in relation to the baroreceptor reflex arc. In Hypertension and Brain Mechanisms. W. de Jong, A. P. Provoost, and A. P. Shapiro, editors. Elsevier Science Publishing Co., Inc., New York. 9-34.

39. Calaresu, F. R., and J. Ciriello. 1980. Projections to the hypothalamus from buffer nerves and nucleus tractus solitarius in the cat. Am. J. Physiol. 239:R130-R136.

40. Morris, M., W. B. Campbell, and W. A. Pettinger. 1976. Renin and hemodynamic changes via central adrenergic, cholinergic, and sodium receptor mechanisms in conscious rats. Proc. Soc. Exp. Biol. Med. 151:101-104.

41. Summy-Long, J. Y., L. M. Rosella, and L. C. Keil. 1981. Effects of centrally administered endogenous opioid peptides on drinking behavior, increased plasma vasopressin concentration and pressor response to hypertonic sodium chloride. Brain Res. 221:343-357.

42. Cowley, A. W., D. Merrill, J. Osborn, and B. J. Barber. 1984. Influence of vasopressin and angiotensin on baroreflexes in the dog. Circ. Res. 54:163-172.

43. Krieger, E. M. 1970. Time course of baroreceptor resetting in acute hypertension. Am. J. Physiol. 218:486-490.

44. Toal, C. B., and F. A. Sunahara. 1982. Effects of central stimulation on reflex bradycardia in the spontaneously hypertensive rat. Clin. Exp. Hypertens. 4:393-410.

45. Morrison, S. F., and D. Whitehorn. 1982. Baroreceptor reflex gain is not diminished in spontaneous hypertension. Am. J. Physiol. 243:R500-R505.

46. Thames, M. D., and B. N. Gupta. 1982. Central nervous system abnormality in baroreflex control of renal nerve activity in renal hypertension. Circulation. 66:II-287.

47. Fujita, T., W. L. Henry, F. C. Bartter, C. R. Lake, and C. S. Delea. 1980. Factors influencing blood pressure in salt-sensitive patients with hypertension. Am. J. Med. 69:334-344.

48. Gotoh, E., E. Miyajima, T. Ohnishi, S. Fujishima, and Y. Kaneko. 1981. Relation of sodium concentrations in cerebrospinal fluid to systemic blood pressure levels in salt-sensitive and nonsaltsensitive essential hypertensive patients. Jpn. Circ. J. 45:998.

49. Campese, V. M., M. S. Romoff, D. Levitan, Y. Saglikes, R. M. Friedler, and S. G. Massry. 1982. Abnormal relationship between sodium intake and sympathetic nervous system activity in salt-sensitive patients with essential hypertension. Kidney Int. 21:371-378. 